induced to produce lysergic acid in culture medium, and that rapeseed contains sulphur compounds which affect the ease of hardening of the oil and have growth-depressant effects when rapeseed meal is fed to livestock.

The Division of Applied Chemistry has a marked interest in metallic corrosion, which has now broadened to include the examination of the formation of metal oxide films at high temperatures. Work in the Division of Pure Chemistry is illustrated by that on the constituents of plants with reputed medicinal action, in which a new photochemical reaction with acid azides was used in the synthesis of the heterocyclic system of diterpenoid alkaloids, and also by that on the thermodynamic properties of some simple molecular crystals at very low temperatures.

In the Division of Applied Physics the development of the temperature scale at very high and very low temperatures continued and excellent progress is reported in thermal conductivity investigations. Better standard light sources are being developed for industrial colorimetry and colour tolerances in the production of coloured materials are also being examined. The outstanding event in the Division of Pure Physics was the establishment of the plasma physics group, but the cosmic-ray group designed a successful instrument package to detect energetio particles in the orbit of the Canadian Earth satellite Alouette, while considerable effort was concen- trated on the de-Haas-von Alphen effect, which consists in magnetic oscillations of magnetic susceptibility as a function of the magnetic field.

Among field research from the Division of Building Research the exploration of the performance of piled foundations in permaforst was a major project, but housing research continues to be pre-eminent. The Division of Mechanical Engineering was concerned with the con. struction at Baie Comeau of a reinforced concrete breakwater, allowing the minimum reflexion of waves. Construction of the National Aeronautical Establishment's 5-ft. supersonic wind-tunnel was completed and considerable effort went to developing a flying simulator for investigating the complex stability and control problems of short- or vertical-take-off and landing aircraft. The Radio and Electrical Engineering Division is investigating corona loss and radio interference, and has designed and built a compact medium-speed transistorized digital computer, using modular transistor-resistor logic throughout.

Besides brief reports from the Medical Research Council and Canadian Patents and Development, Ltd., the report includes the accounts for the year and lists membership of Council, etc. Further details of the work of the Council and of the membership of Committees, etc., together with lists of staff and of publications, are given in the Review of the National Research Council, 1963 (NRC, No. 7426. Ottawa: National Research Council of Canada, 1963).

\title{
COCOA MIRID CONTROL
}

A CONFERENCE at which entomologists and other cocoa research specialists from Cameroun, Ghana, Ivory Coast and Nigeria were present was held at the Cocoa Research Institute at Tafo, Ghana, during August $6-7,1963$, to discuss the recent discovery that some cocoa mirids in Ghana had developed resistance to certain insecticides. Methods being used in Ghana to determine the distribution of resistant mirids and tests to select alternative insecticides to replace lindane were described. Owing to the short notice of the conference, delegates from some West African countries were unable to attend.

Distantiella theobroma (Distant) and Sahlbergella singularis Haglund (Hemiptera: Miridae) caused heavy damage to cocoa trees in Ghana prior to the large-scale use of lindane ( $\gamma$-benzene hexachloride) in 1956. Since spraying began, annual exports of cocoa from Ghana have risen from a former average of about 240,000 tons to an average of 420,000 tons in the past three years. At $£ 150$ per ton (the lowest price reached on the market during 1960-63), this increase in yield would be more than $£ 26$ million each year. This increase has been due in part to the heavier crops produced by mature trees once they are protected from mirid attack, and in part to new plantings, which would have been more difficult to establish had mirids not been controlled.

Since the delegates from Cameroun and the Ivory Coast reported no evidence of insecticide resistance in cocoa mirids in their respective countries, and those from Nigeria had indications of probable resistance in only one small area, all papers were read by workers from Ghana.

Mr. J. N. Telford outlined the history of resistance in Ghana. Failure to control mirids with lindane was noticed first at Pankese Cocoa Station in August 1961, and was shown to be due to the presence of $D$. theobroma resistant to lindane and the cyclodiene insecticides ${ }^{1}$. By January 1963 , resistant $D$. theobroma had been found at three of the other twenty cocoa stations and at one group of private farms. The cocoa stations, which are distributed throughout the cocoa-growing area, have been sprayed four times each year since 1956. The Cocoa Disease and Pest Control Unit of the Ghana Ministry of Agriculture independently surveyed private farms for resistant mirids. One thousand two hundred and seventy-one mirid concentrations, termed 'pockets', were sprayed with increasing strengths of lirrdane within a few days until control was achieved. Mirids in only 37 pockets survived 0.5 per cent lindane applied at the rate of 5 gal. per acre. Confirmation that the survivors in some of these pockets were resistant to lindane was obtained by exposing them to dieldrin-impregnated papers; dieldrin is preferred to lindane because it gives a more sensitive test for resistance. All resistant mirids have come from the main cocoa area, and all pockets in the isolated cocoa area in the Volta Region were controlled by 0.125 per cent lindane. More extensive surveys, using dieldrin papers, are in progress, and results obtained so far from continuous exposure of $D$. theobroma to these papers suggest that a single pair of genes is involved in resistance, but this ean only be confirmed by testing laboratory-reared mirids. Resistance has not been detected in the few $S$. singularis tested in Ghana. In the discussion that followed, it was learned that resistant $S$. singularis had been found in 4 of 118 pockets tested in Nigeria.

Mr. G. Prins described methods recently developed for rearing $D$. theobroma on cocoa seedlings in the laboratory. Females laid more eggs when given only $6 \mathrm{~h}$ of light each day and nymphal mortality was lowest in complete darkness; temperature and humidity were also important factors. $D$. theobroma had been reared through three generations, and about forty progeny per female parent were obtained consistently. An artificial diet had been tried without success. Laboratory investigations on the inheritance of resistance are planned.

Mr. D. G. Peterson described the present field trials of alternative insecticides for the control of cocoa mirids. Mirids resistant to lindane exhibited cross-resistance to the cyclodiene chlorinated hydrocarbon compounds but not to DDT, the organophosphorus insecticides or carbamates. An organophosphorus compound, 'Sumithion' (Imperial Chemical Industries, Ltd.), and a earbamate, 'Sevin' (Union Carbide Chemicals Co.), had given promising results during laboratory tests and preliminary field 
trials. The field performance of both insecticides had been improved by increasing the volume of water from 5 to 10 gal. per acre, and by applying the insecticide directly to the cocoa trees, particularly the trunk and pods, instead of the general dispersion used previously with lindane. A discussion of the several methods that had becn used to evaluate the effectiveness of insecticides for mirid control followed.

Two papers were then read on the possible side-effects of insecticides. Mr. Peterson described precautionary tests carried out to detect whether taint and residues are present in chocolate manufactured from cocoa treated with insecticides. Dr. B. M. Gerard described tests to detect undesirable effects of insecticides on insects other than mirids. It is known that dieldrin ${ }^{2}$, heptachlor and chlordane $e^{3}$ eause increases in numbers of some minor cocoa pests while lindane has not had any obvious sideeffects of this nature. The present tests consisted of monthly applications of 'Sevin', 'Sumithion', lindane and water; after five applications, minor pest populations had not increased noticeably on any of the treated plots, insect pollination seemed unaffected and ants (the most numerous predatory insects on cocoa trees) seemed to be only slightly affected. To minimize the chances of upsetting the ecological balance an insecticide with a narrow spectrum or very short persistence would be preferable.

The final paper on August 6 was a plea by Dr. Gerard for more collaboration between cocoa research stations in West Africa. Cocoa research in the nine West African countries growing this crop was becoming increasingly isolated. Collaboration could prevent unnecessary duplication of experiments, lead to simplification of some investigations and provide an impetus for many lines of research. If entomologists in West Africa could cooperate in a survey of the relationship between cocoa mirids and controlling agents it might be possible to eradicate these species from some areas. In Ghana, $S$. singularis was a major pest only ten years previously, but for at least the past two years had been difficult to find; $D$. theobroma had not decreased to the same extent. Differences between these species include parasitism. 7-31 per cent recorded for $S$. singularis ${ }^{4}$ and virtually nil for $D$. theobroma, and the greater activity of $S$. singularis which could render it more vulnerable to insecticides ${ }^{1}$ He suggested that lindane may have played an important part in this near-eradication, as in addition to being an efficient miridicide it had a short persistence so that any mirids surviving treatment could be attacked by parasites only a few days later. Suggestions were made for improving control of cocoa pests.

Representatives gave details of methods used for mirid control in Nigeria, Ivory Coast and Cameroun, and the importance and distribution of the two mirid species in these countries. It was agreed that collaboration was desirable, and a further conference at Ibadan, Nigeria, has been arranged for March 1964 .

Informal discussions on collaboration continued on August 7. Apparatus and techniques used in insecticide tests and rearing in the laboratories were demonstrated. Mr. A. A. Laryea explained the method for detecting resistant mirids used by the Cocoa Disease and Pest Control Unit previously described by Mr. Telford. The Unit's spraying machine repair shop at Bunso was visited in the afternoon.

The Proceedings of this meeting are now available from the Librarian of the Cocoa Research Institute of Ghana, P.O. Box 8, Tafo, Akim, Ghana.

B. M. Gerard

${ }^{1}$ Dunn, J. A., Nature, 199, 1207 (1963).

2 Entwistle, P. F., Johnson, C. G., and Dunn, E., Nature, 184, 2040 (1959).

${ }^{3}$ Armstrong, K. B., Rep. W. Afr. Cocoa Res. Inst., 1961-62, 28 (1963).

${ }^{4}$ Anon., Rep. W. Afr. Cocoa Res. Inst., 1944-45, 26 (1946).

\section{THE EXPERIMENTAL ANIMAL IN RESEARCH}

$\mathrm{A}^{\mathrm{s}}$ $\mathrm{N}$ advanced study institute on the general topic of "The Experimental Animal in Research" was held in Harrogate during September 9-20, 1963.

The North Atlantic Treaty Organization, which has always shown the greatest interest in fostering international scientific co-operation, financially supported the meeting. It was organized by Dr. W. Lane-Petter, director of the Laboratory Animals Centre (Medical Research Council) and honorary secretary of the International Committee on Laboratory Animals, and his colleagues. There were altogether 90 participants from 17 countries. The idea of the organizers was to create something different from the usual symposia or congresses and provide an atmosphere free from pressure of time. Hence, ample time was allowed to each speaker to reveal his ideas, and the chairman was not compelled to interrupt the discussion of the paper on account of the clock. In addition, all the participants were accommodated in the same hotel and were thus given every opportunity to know each other and to have informal discussions out of working hours. Harrogate, a traditional place for meetings of all kinds, and its surroundings, offered recreations and facilities for excursions.

This advanced study institute was the third of a series of international meetings devoted entirely to laboratory animals. The first meeting of the kind was the symposium on "Living Animal Material for Biological Research"1, held in 1958 at Gif-sur-Yvette (France). The object of this international confrontation was to define the needs of biological research, examine the present situation and see what could be done to meet the demands of modern biology. In 1961, in Czechoslovakia, the second inter- national symposium on "The Problems of Laboratory Animal Disease"2 was held. Disease is the first problem in laboratory animals science. The different papers did not aim at being a complete review of individual diseases as such, but the purpose was mainly to consider, even when dealing with a specific disease, the phenomenon of transmissible diseases in laboratory animals from the point of view of ætiology, epidemiology, control and eradication.

The third subject, "The Experimental Animal in Research", was a very broad one indeed. But it was in fact with design that the institute was not restricted to a specific subject. This was felt to be the best approach to detect all present general trends concerning the needs of modern biological research and the different problems in the production of adequate laboratory animals. In the introductory session, some few examples stressed the importance of the laboratory animal in research and of its shortcomings, the necessity for well-defined laboratory animals and hence the need for a terminology carrying universal acceptance. Then, problems concerning management in general and the different aspects of production were presented by several speakers. Produetion of highquality animals is possible only if a sound organization is set up with adequate facilities and well-trained competent personnel. The production of good laboratory animals is not a problem of husbandry only. There is also the problem of controlling the characteristics for which the animals are produced. It entails complex scientific and technical problems and a galaxy of talents that, of course, cannot be realized in each production unit. Hence the necessity arises of having 'primary type colonies', where the maximum of control is brought to bear on all 